\title{
Descrição fonético-fonológica do Kyikatêjê
}

\author{
Phonetical and phonological description of Kyikatêjê \\ Marília de Nazaré Ferreira Silva \\ Universidade Federal do Pará - Belém - Pará - Brasil
}

\begin{abstract}
Resumo: Este trabalho apresenta um estudo sobre a fonética e fonologia do Kyikatêjê, falada por uma comunidade indígena que possui a mesma denominação, residente na reserva indígena Mãe Maria, sudeste do estado do Pará, a qual ainda não conta com descrição linguística. A metodologia empregada está fundamentada nos pressupostos da Linguística Descritiva, os dados analisados foram coletados na comunidade e a análise é de base pikeana. A presente pesquisa teve também como objetivo a comparação entre línguas geneticamente aparentadas: Parkatêjê e Kyikatêjê.

Palavras-chave: Línguas indígenas; Fonética; Fonologia; Comparação

Abstract: This paper presentes a study about Kyikatêjê Phonetics and Phonology description. This language belongs to the indigenous community with the same denomination, which lives at Reserva Indígena Mãe Maria, southeast of Pará state and it does not have any linguistic description yet. The methodology used is based in Descriptive Linguistics. Data were colected at the village and the analysis is pikean. The present research had also as its objective the comparison between genetically related languages: Parkatêjê and Kyikatêjê.
\end{abstract}

Keywords: Indigenous languages; Phonetics; Phonology; Comparison

\section{Informações sobre os Kyikatêjê e a língua por eles falada}

A comunidade Kyikatêjê faz parte do grupo de povos indígenas que integram a Reserva Indígena Mãe Maria (RIMM). Nesta reserva, encontram-se, além dos Kyikatêjê, os Parkatêjê, os Rõhôkatêjê e os Akrãtikatêjê. Os Kyikatêjê ou "povo do rio acima" também conhecidos como "Turma do Maranhão", segundo a FUNAI (Fundação Nacional do Índio), se autodenominam desta maneira, conforme seu posicionamento ao longo do rio Tocantins. Ferraz $<$ http://pib.socioambiental.org/pt/povo/ gaviao-parkateje/print $>1$, concorda com a informação.

Antes dos Kyikatêjê fixarem moradia na RIMM, eles passaram por uma longa trajetória de constantes conflitos com outros grupos indígenas e, principalmente, com a sociedade não-índia, pela defesa de seu espaço e direitos territoriais e sobretudo culturais. Dos obstáculos presentes na trajetória do povo Kyikatêjê, Fernandes (2010, p. 19) aponta que:

\footnotetext{
1 Endereço eletrônico acessado em 14 de março de 2012.
}

\begin{abstract}
O povo Kyikatêjê teve percurso histórico marcado pela invasão e ocupação do território tradicional pelas mais variadas frentes de ocupação, submetidos às perseguições, tentativas de exterminação e as muitas doenças advindas do contato compulsivo com os não-índios.
\end{abstract}

De acordo com Ricardo (2000), os Kyikatêjê permaneceram sem contato com o SPI (Serviço de Proteção ao Índio) até o início da década de 60. Naquele momento, os Kyikatêjê residiam numa área conhecida como Igarapés dos Frades, próximo à cidade de Imperatriz, sudoeste do Maranhão. Durante a década de 60 houve algumas tentativas de contato e, somente por volta de 1969, houve o contato definitivo e a remoção do grupo para a Reserva Indígena Mãe Maria (RIMM).

A ação de integrar esse grupo a outro grupo timbira, em um único lugar, realizada pelo SPI e FUNAI, tendo como intermediador dessa união o líder Krôhôkrenhum (chefe do povo Parkatêjê), teve o objetivo de fortalecer e resgatar a cultura dos três povos que se encontravam enfraquecidos: os Akrãtikatêjê, os Rõhôkatêjêe os Kyikatêjê. 
Durante a trajetória dos Kyikatêjê do Maranhão até o Pará, o povo constituiu moradia em diversos lugares (aproximadamente doze lugares distintos) até permanecerem por mais de 20 anos junto aos Parkatêjê. Em meio ao tempo em que compartilharam o mesmo território, eles construíram fortes laços fraternos, por serem pertencentes a uma mesma origem linguística e cultural e também por promoverem casamentos entre membros dos dois grupos. Dessas uniões, há hoje netos e bisnetos, o que evidencia também o crescimento do povo.

Durante o tempo de convivência entre eles, sempre mencionavam suas diferenças: a mais concreta delas - a linguística. À primeira vista, as diferenças linguísticas são mínimas, no entanto é necessário empreender estudos mais detalhados sobre aspectos centrais das línguas para verificar em que medida se assemelham ou se diferenciam. Para exercer sua autonomia, que dizia respeito ao desejo de ter sua própria aldeia, os Kyikatêjê fizeram uso desta diferença. Assim, em 2001, os dois grupos se separaram, passando cada um a viver em locais distintos, localizados na mesma terra indígena.

Com a separação, os Parkatêjê continuam vivendo na altura do $\mathrm{Km}$ 30, enquanto os Kyikatêjê, no Km 25, da BR-222. No entanto, há índios Kyikatêjê que optaram por continuar na antiga aldeia, com os Parkatêjê, pois mesmo com a separação o laço de amizade construído entre os grupos é permanente.

Segundo Fernandes (2010, p. 32), a aldeia Kyikatêjê foi constituída em 2001 numa área onde funcionava o projeto agropecuário da associação Parkatêjê. O local era usado para plantio de alimentos e criação de animais. Conforme assegura Fernandes (2010, p. 32), os primeiros meses na nova aldeia foram concebidos como "tempos difíceis" pela falta de recursos e de alimentos, porém foram também momentos de alegria e de grande união entre o povo, e acima de tudo, de celebração da cultura. As primeiras casas construídas na nova aldeia eram feitas de lâminas de compensado e cobertas com palha. Tais construções improvisadas foram substituídas por casas de madeira, e, no ano de 2007, com o apoio da VALE e, através do convênio entre esta empresa e a associação da aldeia, houve a construção das casas, desta vez, em alvenaria.

A aldeia Kyikatêjê, desde as primeiras moradias, foi construída conforme o padrão macro-jê, ou seja, em formato circular, correspondente ao que afirma Melatti (1974) sobre a organização das casas nas aldeias timbira:

Nas aldeias timbira, as casas se dispõem uma ao lado da outra, ao longo de um largo caminho, de modo a formar um grande círculo. De cada casa sai um caminho, mais estreito, em direção ao centro, onde está o pátio. [...]. O pátio é o local das reuniões masculinas, ao amanhecer e ao anoitecer. Nele as mulheres cantam dispostas em fila, ombro a ombro, conduzidas por um cantor que agita o maracá.

De acordo com Soares e Farias (2011), a população é composta por aproximadamente 300 pessoas. A maioria é Kyikatêjê (cerca de 145 indivíduos); havendo índios Akrãtikatêjê, Guarani, Guajajara, Karajá, Kaingang, Krikati, Parkatêjê, Terena, Wayãpi e Xerente. As faixas etárias da população são diversas, indo de 60 a menos de 01 ano de idade, segundo as referidas autoras. A comunidade é liderada pelo cacique Kykyiré, também atual presidente da Associação Indígena Gavião Kyikatêjê Amtàti e responsável principal pela organização do povo no que diz respeito às festas tradicionais e reuniões sobre a comunidade.

O povo Kyikatêjê fala uma variedade linguística muito próxima do Parkatêjê, que juntamente com Krahô, Krinkati, Canela Ramkókamekra, Canela Apanyekrá, Gavião-Pykobjê e Apinayé, constituem um grupo de línguas que Rodrigues (1999) chamou de "Complexo dialetal Timbira", pertencente à família Jê, do tronco linguístico Macro-Jê.

O presente estudo e outros trabalhos foram desenvolvidos no âmbito do projeto "Descrição de aspecto fonético-fonológico, morfossintáticos e lexicais do Kyikatêjê" (Processo $n^{\circ} 401116 / 2010-7$ CNPq), coordenado por Marília Ferreira (UFPA). Da perspectiva linguística, pode-se afirmar, com base em evidências fonético-fonológicas e lexicais que não se tratam de línguas distintas. Todavia os indígenas afirmam a distinção, com especial ênfase no aspecto linguístico, para marcar seu estatuto como povo. Daí que a utilização do termo "língua", quando referido aos falares que compõem o complexo dialetal timbira, é feita para estar de acordo com a maneira com que os povos indígenas se referem ao código linguístico por eles utilizado. Desta maneira, para os indígenas, a definição de "língua" funciona como um instrumento de afirmação identitária e, sobretudo, de atitude política. No caso dos Kyikatêjê, essa afirmação é de grande relevância, uma vez que se separaram dos Parkatêjê a menos de 15 anos, e necessitam ser compreendidos como um povo independente.

Este trabalho especificamente consiste na descrição de aspectos fonético-fonológicos do Kyikatêjê, com base na teoria linear utilizando os procedimentos de análise descritiva de Kenneth Pike (1947), apresentados por Kindell (1981). Para conhecimento das comunidades, foram utilizados os trabalhos de Araújo $(1977,1989)$, Ferreira (2005) e de Fernandes (2010). 


\section{Considerações sobre fonética e fonologia}

A fonética, de modo geral, é responsável pelo estudo das propriedades sonoras que são produzidas pela fala, das condições fisiológicas necessárias para a produção dos sons e maneira como estes são percebidos. Neste sentido, a Fonética se ocupa em estudar os "sons como unidades físico-articulatórias isoladas, ou seja, independentemente de suas oposições e aplicações paradigmáticas", como afirmam Callou e Leite (2001, p. 11):

A unidade de estudo da fonética é o som da fala ou fone. Desse modo, cabe à fonética, descrever e analisar os sons atribuindo atenção às particularidades articulatórias, acústicas e perceptivas da linguagem falada (CALLOU e LEITE, 2001, p. 11).

Ela possui como áreas de interesse: a fonética articulatória - estuda da produção da fala do ponto de vista fisiológico e articulatório; a fonética auditiva - a percepção da fala; a fonética acústica - estuda as propriedades físicas dos sons da fala a partir da transmissão do falante ao ouvinte; e, a fonética instrumental - estuda as propriedades físicas dos sons da fala, considerando o apoio de instrumentos laboratoriais, de acordo com Silva (2010, p. 23).

A Fonética Articulatória promove a descrição dos sons levando em consideração os pontos e modos de articulação, com relação às consoantes, e altura e posição da língua, no caso das vogais.

Ao observar a produção do som no trato vocal, podese estabelecer, por exemplo, a separação entre os sons consonantais e vocálicos, entendidos como estágios de abertura por onde o ar passa livremente ou não, em que a passagem de ar pode ser parcialmente ou completamente impedida (SCHANE, 1973). Por meio da observação da produção articulatória dos sons do Kyikatêjê, serão apresentados a seguir os sons presentes na língua e suas implicações fonéticas, tanto para os sons vocálicos quanto para os consonantais.

Os estudos fonológicos da língua Kyikatêjê foram embasados na teoria linear. Tais estudos foram atribuídos aos procedimentos de descoberta propostos por Keneth Pike (1947) e os apresentados em Kindell (1981). Esta abordagem se justifica pelo fato de o Kyikatêjê nunca ter sido anteriormente estudado. Deste modo, pretende-se, com este trabalho, apresentar uma descrição da fonologia da língua.

Por meio da aplicação dos procedimentos da teoria pikeana são reveladas as particularidades distintivas de cada som presente na língua estudada. Assim, com base nos métodos desta teoria, podem-se identificar os fonemas e seus alofones bem como seus comportamentos linguísticos dentro do ambiente em que ocorrem. De acordo com Pike (1947), a descrição das unidades êmicas necessita de critérios como contraste, variação livre e distribuição complementar.

Kindell (1981) apresenta um resumo dos procedimentos postulados por Pike. Segundo a autora, as unidades êmicas são descritas:

em termos de três aspectos: o contraste, a variação e a distribuição. $\mathrm{Na}$ análise de um determinado sistema fonológico, aplica-se cada um dos três aspectos aos mesmos dados físicos, a fim de estudar a estrutura, simultaneamente, de três pontos de vista. Cada aspecto se vê somente em relação a um sistema que abrange todos os três de uma maneira interrelacionada.

\subsection{Os sons vocálicos da língua Kyikatêjê}

O Kyikatêjê tem 17 sons vocálicos. Esse mesmo número é o do Parkatêjê (Araújo, 1977 p. 115), do Tapayúna (CAMARGO, 2010, p. 41) e do Pykobjê (AMADO, 2004, p. 16), entre outras línguas macro-jê.

Uma característica comum a essas línguas diz respeito ao número de sons vocálicos que é predominantemente maior em relação aos consonantais. No caso da língua Kyikatêjê são 33 sons:17 vocálicos e 16 consonantais. Dos sons vocálicos, 11 são orais e 06 são nasais

A partir da análise dos dados, o seguinte quadro de sons vocálicos da língua pode ser organizado:

Quadro 1 - Sons vocálicos da língua Kyikatêjê.

\begin{tabular}{|l|c|c|c|c|c|c|}
\hline & \multicolumn{2}{|c|}{ Anteriores } & \multicolumn{2}{c|}{ Centrais } & \multicolumn{2}{c|}{ Posteriores } \\
\hline & Orais & Nasais & Orais & Nasais & Orais & Nasais \\
\hline Altas Fechadas & i I & $\tilde{\imath}$ & $\dot{\dagger}$ & $\tilde{\mathrm{f}}$ & $\mathrm{u}$ & $\tilde{\mathrm{u}}$ \\
\hline Médias Fechadas & $\mathrm{e}$ & $\tilde{\mathrm{e}}$ & $\partial$ & $\tilde{\mathrm{a}}$ & 0 & $\tilde{0}$ \\
\hline Médias Abertas & $\varepsilon$ & & 3 & & 0 & \\
\hline Baixas Abertas & & & $\mathrm{a}$ & & & \\
\hline
\end{tabular}

\subsubsection{Descrição dos sons vocálicos orais}

Os sons vocálicos orais do Kyikatêjê são 11 vogais (04 anteriores, 04 centrais e 03 posteriores), "um sistema recorrente nas línguas Timbira", conforme Rodrigues (1999).

Quadro 2 - Sons vocálicos orais

\begin{tabular}{|l|c|c|c|}
\hline & Anteriores & Centrais & Posteriores \\
\hline Altas Fechadas & i I & $\dot{\mathrm{t}}$ & $\mathrm{u}$ \\
\hline Médias Fechadas & $\mathrm{e}$ & ə & 0 \\
\hline Médias Abertas & $\varepsilon$ & 3 & 0 \\
\hline Baixas Abertas & & $\mathrm{a}$ & \\
\hline
\end{tabular}


Os sons vocálicos anteriores, centrais e posteriores ocorrem como núcleo de sílaba inicial, medial e final. Somente o som vocálico [I] possui uma ocorrência diferenciada, ocorrendo no início e final de sílaba diante de $[a]$ e $[\varepsilon]$. Vejamos os exemplos abaixo:

1. [i]: anterior, alta, fechada, não-arredondada.
(1) [i.'to]
'olho'
(2) [ĩn.kri.'re
'pequeno'
(3) [i.pa'hi]
'antebraço'

2. [I]: anterior, alta, fechada, não-arredondada.
(4) $\left[\mathrm{ar} .{ }^{\prime} \mathrm{kr \varepsilon}\right]$
'casa'
(5) [ar.'te.jõ'kra]
'mão deles'
(6) [ko.koi.'peI]
'macaco prego'

3. [e]: anterior, média, fechada, não-arredondada.
(7) [te.'ti]
'lontra'
(8) $[$ te.re.'re]
'açaí'
(9) $[\mathrm{ku}$. 'he]
'arco'

4. [ع]: anterior, média, aberta, não-arredondada.
(10) $[\mathrm{t} \varepsilon \mathrm{p}]$
'peixe'
(11) [ar.'te.jõ.'kra]
'mão deles'
(12) [ka.fe.'re]
'estrela'

5. [i]: central, alta, fechada, não-arredondada.
(13) $[\mathrm{pit}]$
'sol'
(14) [pi.pi.'tfo]
'banana'
(15) [ku.'pit]
'guariba'

6. [ə]: central, média, fechada, não-arredondada.
(16) $[\mathrm{pər}]$
'árvore'
(17) [po.tə're]
'formiga'
(18) [i.'kə]
'pele'

7. [3]: central, média, aberta, não-arredondada.
(19) [hз.ka.'ti]
'jiboia'
(20) [p3.t3.'ti]
'tamanduá'
(21) [ar.kwa.'k3]
'lábio’

8. [a]: central, baixa, aberta, não-arredondada.
(22) [ka.'krõ]
'céu'
(23) [ko.ka.'pe]
'vento'
(24) [a.'fa]
'morder'

9. [u]: posterior, alta, fechada, arredondada.
(25) $\left[\mathrm{ku} .{ }^{\prime} \mathrm{kre} e \tilde{}\right]$
'comer'
(26) [ju.nu.'re]
'beija-flor'
(27) [i.'tu]
'barriga'

10. [o]: posterior, média, fechada, arredondada.
(28) [ko]
'água'
(29) [am.fo.'re] 'rato'
(30) [i.'tfot] 'pênis'

11. [0]: posterior, média, aberta, arredondada.
(31) [rop]
'cachorro'
(32) [i.na.kõ.kõ.no.'rع] 'coração'
(33) [i.'to]
'olho'

\subsubsection{Descrição dos sons vocálicos nasais}

Os segmentos vocálicos nasais encontrados nos dados são os que seguem:

Quadro 3 - Sons vocálicos nasais

\begin{tabular}{|l|c|c|c|}
\hline & Anteriores & Centrais & Posteriores \\
\hline Altas Fechadas & $\tilde{\mathrm{I}}$ & $\tilde{\mathrm{I}}$ & $\tilde{\mathrm{u}}$ \\
\hline Médias Fechadas & $\tilde{\mathrm{e}}$ & $\tilde{\partial}$ & $\tilde{0}$ \\
\hline
\end{tabular}

Os sons vocálicos nasais, assim como os orais, correm em sílabas iniciais, mediais e finais, como podemos observar nos dados abaixo.

1. [ĩ]: anterior, alta, fechada, não-arredondada, nasal.
(34) $[$ ĩ̃.'re]
'jacaré'
(35) [ĩpakrĩ't๖
'banco/cadeira'
(36) [õ.'hĩ]
'buzina'

2. [ẽ]: anterior, média, fechada, não-arredondada, nasal.
(37) [kẽn]
'pedra'
(38) [pi.tẽk.'ti]
'mutum'
(39) $[\mathrm{ku}$. 'krẽ $]$
'comer'

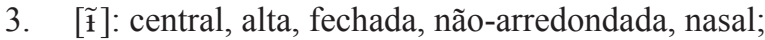
(40) $\left[3^{\tilde{1}}\right]$
'sentar'
(41) [a.kr̃̃. .'ti]
'branco'
(42) [pa.mũ.' $3 \tilde{\mathrm{p}}$ ]
'eu sentei'

4. [ə̃]: central, média, fechada, não-arredondada, nasal.

(43) $[\mathrm{krã}] \quad$ 'cabeça'
(44) [a.krã.'ti] 'montanha'
(45) [ka.'prõn] 'jabuti'

5. [ũ]: posterior, alta, fechada, arredondada, nasal
(46) [mũ.'tẽ]
'vai'
(47) [pa.mũ.' $3 \tilde{\text { 1 }]}$
'eu sentei'
(48) [õ.'pũ]
'ver'

6. [õ]: posterior, média, fechada, arredondada, nasal.
(49) [õ.'ksp]
'unha'
(50) [i.na.kõ.kõ.no'r\&]
'coração'
(51) [wa.'kõ]
'quati'

\subsubsection{Descrição dos sons consonantais da língua}

No quadro a seguir estão presentes os 16 sons consonantais da língua Kyikatêjê, comuns às línguas Timbira-Jê. 
Quadro 4 - Sons consonantais da língua Kyikatêjê

\begin{tabular}{|c|c|c|c|c|c|}
\hline & Bilabiais & Alveolares & Palatal & Velares & Glotais \\
\hline Oclusivas & $p$ & $\mathrm{t}$ & & k $\quad \mathrm{k}^{\mathrm{j}}$ & $?$ \\
\hline Africada & & & t & & \\
\hline Fricativas & $\beta$ & & 3 & & $\mathrm{~h}$ \\
\hline Nasais & $\mathrm{m} \quad \mathrm{mp}$ & $\mathrm{n}$ & & $\eta$ & \\
\hline Tepe ou flap & & $r$ & & & \\
\hline Aproximantes & w & & j & & \\
\hline
\end{tabular}

\subsubsection{Descrição dos sons consonantais e suas ocorrências}

Os sons consonantais do Kyikatêjê são descritos em oclusivas, africada, fricativas, nasais, tepe e aproximantes.

Os sons oclusivos do Kyikatêjê [p], [t], [k], todos desvozeados, ocorrem na posição de onset e coda de sílaba inicial, medial e final. Há uma particularidade de ocorrência diante de $[\mathrm{r}]$ envolvendo as oclusivas $[\mathrm{p}] \mathrm{e}[\mathrm{k}]$ : nesta realização, ambas também ocorrem em posição de onset de sílaba inicial, medial e final. Outra particularidade das oclusivas diz respeito ao fato de que, quando estão em posição de coda, são levemente aspiradas. [k] também ocorre com palatalização [kj], em onset de sílaba final.

Também foi encontrada a oclusiva glotal [?] ocorrendo em posição de onset de sílaba medial. Esse fone [?] foi encontrado somente na palavra [a?ã' $r \varepsilon]$ que quer dizer 'galinha'. Segundo Araújo (2008, p. 216) é uma onomatopeia, por ser "um nome de animal cuja formação remete à reprodução - evidentemente cultural - do som por ele emitido". Como tal som foi encontrado somente em uma palavra, ele não será analisado fonologicamente. Os exemplos dos sons oclusivos em Kyikatêjê seguem abaixo:

1. [p]: consoante oclusiva, bilabial, desvozeada.

- Em posição de onset
(52) [pər]
'árvore'
(53) [pi.pi.'tfo]
'banana'
(54) [ko.ka.'pe] 'vento'
- Em posição de coda

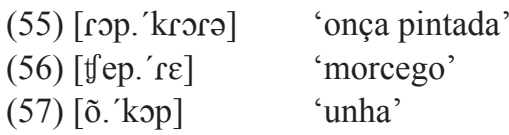

2. [t]: consoante oclusiva, alveolar, desvozeada.

- Em posição de onset
(58) [te.'ti]
'lontra'
(59) [рз.tз.'ti]
'tamanduá'
(60) [ka.'ti]
'rio'

- Em posição de coda

$\begin{array}{ll}\text { (61) }[\mathrm{krət}] & \text { 'nariz' } \\ \text { (62) [i.'put] } & \text { 'pescoço' } \\ \text { (63) }[\text { i.'tfot] } & \text { 'pênis' }\end{array}$

3. [k]: consoante oclusiva, velar, desvozeada.

- Em posição de onset
(64) [ka.'prə̃n]
'jabuti'
(65) [ko.ka.'pe] 'vento'
(66) [ar.kwa.'k3] 'lábio
(67) $\left[\mathrm{i}^{\prime} \mathrm{k}^{\mathrm{j}} \mathrm{e}\right] \quad$ 'coxa'

- Em posição de coda
(68) [tik.'ti]
'preto'
(69) [pi.' 'tẽk.ti]
'mutum'
(70) [ja.'pak]
'orelha'

4. [?]: consoante oclusiva, glotal.

(71) [a.१ว̃.'rع] 'galinha'

O Kyikatêjê apresenta somente uma consoante africada. Trata-se da africada, palatal, desvozeada [ $\mathrm{t}$ ] . Ocorre em posição de onset de sílaba inicial, medial e final.
(72) $[\mathrm{a} . \mathrm{t} \mathrm{fa}]$
'morder'
(73) [jõ.taw.'tə]
'estômago'
(74) [mpo.'to]
'fruto'
(75) [t 'ep.'re]
'morcego'
(76) $[\mathrm{ka} . f \mathrm{e} . \mathrm{\prime} r \varepsilon]$
'estrela'
(77) [po.tə.' $\mathrm{s}]$
'formiga'

O Kyikatêjê apresenta três sons fricativos: $[\beta]$,

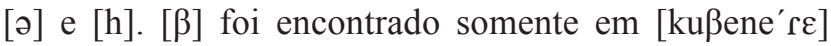
'pássaro'; o mesmo não será analisado fonologicamente. [3] ocorre em posição de onset de sílaba inicial e final e [h] ocorre em posição de onset de sílaba inicial, medial e final e na posição de coda de sílaba final. Seguem os exemplos:

1. [B]: consoante fricativa, bilabial, vozeada.

(78) [ku.ße.ne.'re] 'pássaro' 
2. [3]: consoante fricativa, pós-alveolar, vozeada.
(79) $\left[3^{\tilde{1}}\right]$
'sentar'
(80) [mps.'3ĩ]
'carne'

3. [h]: consoante fricativa, glotal, desvozeada.

- Em posição de onset
(81) [he.'ti]
'aranha'
(82) [ka.hə.'kri] 'mau'
(83) [õ.'hĩ] 'buzina'
• Em posição de coda
$\begin{array}{ll}\text { (84) }[\text { pih] } & \text { 'urucum' } \\ \text { (85) [mẽ.'pih] } & \text { 'homem' }\end{array}$

Os sons nasais do Kyikatêjê classificam-se em bilabial, alveolar e velar. Os sons nasais são: [m], [n] e [y]. Os sons [m], [n] ocorrem em posição de onset de sílaba inicial, medial e final; porém, em posição de coda, [m] ocorre em sílaba inicial, medial e final, e, [n] somente em sílaba final. Há também a ocorrência de [m] diante de [p]. Esta realização [mp] se dá em posição de onset de sílaba inicial.

A consoante nasal velar [y] ocorre em posição de coda de sílaba inicial. Este fone aparece somente no dado [ĩjkri'rع], o qual é falado por um informante idoso. O mesmo item lexical é recorrente com a nasal alveolar [ĩnkri'rع]. Essa realização foi observada na fala de dois informantes: um de 45 anos aproximadamente e uma senhora idosa. Observa-se então, que no caso de [y], ocorreu uma assimilação decorrente da presença de [k]. Desta maneira, o fone não aparecerá na análise fonológica.

Os exemplos mostram a ocorrência dos sons nasais em Kyikatêjê:

1. [m]: consoante nasal, bilabial.

- Em posição de onset
(86) [mĩ.' 're]
'jacaré'
(87) [i.ma.'krit]
'frio'
(88) [ta'mri]
'isso'
- Em posição de coda
(89) [am.tfo.'re] 'rato'
(90) [am.nẽ.' 'tẽ] 'vem'
(91) [jũm.'nã] 'quem'

2. [n]: consoante nasal, alveolar.

- Em posição de onset
(92) [nũ.a.'re]
'não
(93) [i.na.kõ.kõ.no.'rع]
(94) [jũm.'nã]
'coração'
'quem'
- Em posição de coda
$\begin{array}{ll}\text { (95) }[\mathrm{kẽn}] & \text { 'pedra' } \\ \text { (96) [ka.'prãn] } & \text { 'jabuti' } \\ \text { (97) [i.te.'kon] } & \text { 'joelho' }\end{array}$

3. [y]: consoante nasal, velar.

(98) [ĩn.kri.'rع] 'pequeno'
O Kyikatêjê apresenta a consoante tepe alveolar [r], que ocorre em posição de onset em sílaba inicial, medial e final; e na posição de coda de sílaba inicial e final.

- Em posição de onset

$\begin{array}{ll}\text { (99) [rop] } & \text { 'cachorro' } \\ \text { (100) [te.re.'re] } & \text { 'açaí' } \\ \text { (101) [a.'re] } & \text { 'raiz' } \\ \text { • Em posição de coda } & \\ \text { (102) [or.per.ti] } & \text { 'sapo' } \\ \text { (103) [ar.'kwa] } & \text { 'boca' } \\ \text { (104) [i.'par] } & \text { 'pé' }\end{array}$

Os sons aproximantes [w] e [j] classificam-se em bilabial e palatal, respectivamente. [w] ocorre em posição de onset sílaba inicial, medial e final; em posição de coda, ocorre em sílaba inicial e final. [j] ocorre somente em posição de onset de sílaba inicial e medial.

1. [w]: aproximante, bilabial, vozeada.

- Em posição de onset
(105) [wa.'kõ]
'quati'
(106) [ku.wa'ti] 'coruja'
(107) ['kru.wa] 'flecha'
- Em posição de coda
(108) [aw.'rị] 'chuva'
(109) [jõ.ffaw.fə] 'estômago'

2. [j]: aproximante, palatal, vozeada.
(110) [ja.'pak] 'orelha'
(111) [jõ.ku.'he] 'meu arco'
(112) [jo.jo.to.'ti] 'tucano'
(113) [ju.nu.'re] 'beija-flor'

A partir da transcrição dos dados e de sua observação, foi possível arrolar os segmentos fônicos vocálicos e consonantais ora apresentados e descritos.

\section{Os fonemas da língua Kyikatêjê}

Com base no procedimento de contraste de sons em pares mínimos e análogos, foram definidos vinte e seis fonemas na língua Kyikatêjê, divididos em 10 consoantes e 16 vogais. Das consoantes, 03 são oclusivas desvozeadas, com pontos de articulação bilabial /p/, alveolar /t/ e velar /k/; 02 são nasais, com ponto de articulação bilabial /m/ e alveolar /n/; 01 é africada com ponto de articulação palatal $/ \mathrm{f} / ; 01$ tepe /r/; 01 é fricativa, com ponto de articulação glotal /h/; 02 são aproximantes com pontos de articulação labiovelar $/ \mathrm{w} /$ e palatal $/ \mathrm{j} /$.

Das 16 vogais: 10 são orais e 06 são nasais. As orais são /i/, /ì/, /u/, /e/, /a/, /o/, /E/, /3/, /o/ e /a/; as nasais, /î/, $\tilde{\mathrm{t}} /, / \tilde{\mathrm{u}} /, / \tilde{\mathrm{e}} /, / \tilde{\mathrm{a}} /$, e $/ \tilde{\mathrm{o}} /$. As vogais orais contrastam em 03 alturas: alta, média e baixa, já as nasais contrastam em alta e média. $\mathrm{O}$ arredondamento de lábios se dá nas vogais posteriores, não ocorrendo nas vogais anteriores. 
Os fonemas consonantais e vocálicos da língua Kyikatêjê estão nos Quadros 5 e 6, a seguir.

Quadro 5 - Fonemas consonantais da língua Kyikatêjê

\begin{tabular}{|l|c|c|c|c|c|c|}
\hline & Bilabial & Labiovelar & Alveolar & Palatal & Velar & Glotal \\
\hline Oclusiva & $/ \mathrm{p} /$ & & $/ \mathrm{t} /$ & & $/ \mathrm{k} /$ & \\
\hline Africada & & & & $/ \mathrm{f} /$ & & $/ \mathrm{h} /$ \\
\hline Fricativa & & & & & & \\
\hline Nasal & $/ \mathrm{m} /$ & & $/ \mathrm{n} /$ & & & \\
\hline Tepe & & & $/ \mathrm{r} /$ & & & \\
\hline Semiconsoante & & $/ \mathrm{w} /$ & & $/ \mathrm{j} /$ & & \\
\hline
\end{tabular}

Quadro 6 - Fonemas vocálicos da língua Kyikatêjê

\begin{tabular}{|l|c|c|c|c|c|c|}
\hline \multirow{2}{*}{} & \multicolumn{2}{|c|}{ Anteriores } & \multicolumn{2}{c|}{ Centrais } & \multicolumn{2}{c|}{ Posteriores } \\
\cline { 2 - 7 } & Orais & Nasais & Orais & Nasais & Orais & Nasais \\
\hline Altas fechadas & $/ \mathrm{i} /$ & $/ \mathrm{i} /$ & $/ \mathrm{i} /$ & $/ \tilde{\mathrm{t}} /$ & $/ \mathrm{u} /$ & $/ \tilde{\mathrm{u}} /$ \\
\hline Médias fechadas & $/ \mathrm{e} /$ & $/ \tilde{\mathrm{e}} /$ & $/ \mathrm{a} /$ & $/ \tilde{\mathrm{a}} /$ & $/ \mathrm{o} /$ & $/ \mathrm{o} /$ \\
\hline Médias abertas & $/ \varepsilon /$ & & $/ 3 /$ & & $/ \mathrm{l} /$ & \\
\hline Baixas abertas & & & $/ \mathrm{a} /$ & & & \\
\hline
\end{tabular}

Os exemplos de contrastes demonstrados a seguir estão dispostos, respectivamente, com suas transcrições fonética e fonológica, juntamente com seus correspondentes em língua portuguesa.

\subsection{Contraste entre os sons consonantais}

\begin{tabular}{|c|c|c|}
\hline Fonética & Fonologia & Português \\
\hline $\begin{array}{l}/ \mathbf{p} /: \text { / } / \mathbf{m} / \\
\quad(114)[\text { pa.'ho] } \\
\quad(115)[\text { ma.'ho] }\end{array}$ & $\begin{array}{l}\text { /paho/ } \\
\text { /maho/ }\end{array}$ & $\begin{array}{l}\text { 'cabelo do braço' } \\
\text { 'barba' }\end{array}$ \\
\hline 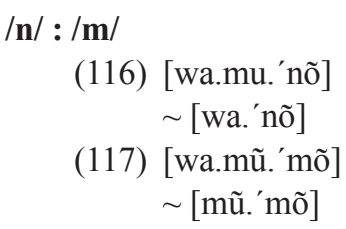 & $\begin{array}{l}\text { /wamunõ/ } \\
\text { /wamũmõ/ }\end{array}$ & $\begin{array}{l}\text { 'deitar' ou } \\
\text { 'nós deitamos' } \\
\text { 'andar' ou } \\
\text { 'nós andamos' }\end{array}$ \\
\hline $\begin{aligned} / \mathbf{k} /: & / \mathbf{t} / \\
& (118)[\mathrm{t} \text { a.'re] } \\
& (119)[\mathrm{ka} \cdot \mathrm{\prime} \text { re] }\end{aligned}$ & $\begin{array}{l}\text { /fare/ } \\
\text { /kare/ }\end{array}$ & $\begin{array}{l}\text { 'macaco amarelo } \\
\text { 'roçar' }\end{array}$ \\
\hline $\begin{aligned} / \mathbf{n} /: & / \mathbf{r} / \\
& (120)[\text { ke.ne.'re] } \\
& (121) \text { [te.re.'re] }\end{aligned}$ & $\begin{array}{l}\text { /kenere/ } \\
\text { /terere/ }\end{array}$ & $\begin{array}{l}\text { 'a pessoa que não } \\
\text { sabe' } \\
\text { 'açaí' }\end{array}$ \\
\hline $\begin{array}{l}/ \mathbf{t} /: \text { / } / \mathbf{f} \\
\quad(122)[\mathrm{ka} . ' \mathrm{te}] \\
\\
\quad(123)[\mathrm{ka} . ' \mathrm{re}]\end{array}$ & $\begin{array}{l}\text { /kate/ } \\
\text { /kare/ }\end{array}$ & $\begin{array}{l}\text { 'valente' } \\
\text { 'roçar' }\end{array}$ \\
\hline
\end{tabular}

\begin{tabular}{|c|c|c|}
\hline Fonética & Fonologia & Português \\
\hline 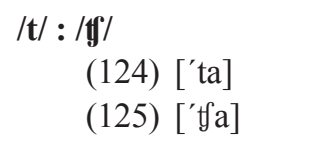 & $\begin{array}{l}/ \mathrm{ta} / \\
\mathrm{/t} \mathrm{a} /\end{array}$ & $\begin{array}{l}\text { 'cortar' } \\
\text { 'estar de pé' }\end{array}$ \\
\hline $\begin{array}{l}\mathbf{m} / \mathbf{~} / \mathbf{w} / \\
\quad(126)[\mathrm{ma} . ' \mathrm{ho}] \\
\\
\quad(127)[\text { wa.'kõ] }\end{array}$ & $\begin{array}{l}\text { /maho/ } \\
\text { /wakõ/ }\end{array}$ & $\begin{array}{l}\text { 'barba' } \\
\text { 'quati' }\end{array}$ \\
\hline
\end{tabular}

\subsection{Contraste entre os segmentos vocálicos}

\begin{tabular}{|c|c|c|}
\hline Fonética & Fonologia & Português \\
\hline $\begin{array}{l}/ \mathbf{i} /: \text { /e/ } \\
\qquad \begin{array}{l}(128)[\mathrm{ka} . ' \mathrm{ti}] \\
\\
(129)\left[\mathrm{ka} .{ }^{\prime} \mathrm{te}\right]\end{array}\end{array}$ & $\begin{array}{l}\text { /kati/ } \\
\text { /kate/ }\end{array}$ & $\begin{array}{l}\text { 'rio' } \\
\text { 'valente, dono' }\end{array}$ \\
\hline $\begin{array}{l}/ \mathbf{e} /: \text { / } \boldsymbol{\varepsilon} / \\
\qquad \begin{array}{l}(130)\left[\mathrm{ka} .{ }^{\prime} \mathrm{te}\right] \\
(131)\left[\mathrm{ka} .{ }^{\prime} \mathrm{t} \varepsilon\right]\end{array}\end{array}$ & $\begin{array}{l}\text { /kate/ } \\
\text { /kate/ }\end{array}$ & $\begin{array}{l}\text { 'valente, dono' } \\
\text { 'rachar' }\end{array}$ \\
\hline $\begin{aligned} / \mathbf{\partial} /: & / \mathbf{3} / \\
& (132)[\text { ['pən] } \\
& (133)[\text { 'p3r] }\end{aligned}$ & $\begin{array}{l}\text { /pən/ } \\
\text { /p3r/ }\end{array}$ & $\begin{array}{l}\text { 'arara' } \\
\text { 'pau' }\end{array}$ \\
\hline $\begin{array}{l}/ 3 / \text { : /a/ } \\
\text { (134) [i.p3.ra sũn'ti] } \\
\text { (135) [i.pa'hi] }\end{array}$ & $\begin{array}{l}\text { /ipзrarũnti/ } \\
\text { /ipahi/ }\end{array}$ & $\begin{array}{l}\text { 'grosso' } \\
\text { 'dedo do pé' }\end{array}$ \\
\hline
\end{tabular}




\begin{tabular}{|c|c|c|}
\hline Fonética & Fonologia & Português \\
\hline $\begin{aligned} / \mathbf{0} /: & / \mathbf{o} / \\
& (136)[\mathrm{ko}] \\
& (137)[\mathrm{ko}]\end{aligned}$ & $\begin{array}{l}\text { /ko/ } \\
/ \mathrm{kJ} /\end{array}$ & $\begin{array}{l}\text { 'água' } \\
\text { 'molhar' }\end{array}$ \\
\hline $\begin{aligned} / \mathbf{i} /: & / \mathbf{i} / \\
& (138)\left[{ }^{\prime} \mathrm{hi}\right] \\
& (139)\left[{ }^{\prime} \mathrm{hi}\right]\end{aligned}$ & $\begin{array}{l}\text { /hi/ } \\
/ \mathrm{hi} /\end{array}$ & $\begin{array}{l}\text { 'semente' } \\
\text { 'osso' }\end{array}$ \\
\hline $\begin{aligned} / \mathbf{i} /: & / \mathbf{u} / \\
& (140) \text { [i.'put] } \\
& (141) \text { [a.'pih] }\end{aligned}$ & $\begin{array}{l}\text { /iput/ } \\
\text { /apih/ }\end{array}$ & $\begin{array}{l}\text { 'pescoço’ } \\
\text { 'rabo’ }\end{array}$ \\
\hline 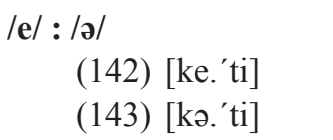 & $\begin{array}{l}\text { /keti/ } \\
\text { /kəti/ }\end{array}$ & $\begin{array}{l}\text { 'avô' } \\
\text { 'pitiú' }\end{array}$ \\
\hline 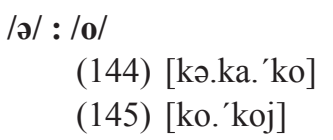 & $\begin{array}{l}\text { /kəkako/ } \\
\text { /kokoj/ }\end{array}$ & $\begin{array}{l}\text { 'leite' } \\
\text { 'macaco' }\end{array}$ \\
\hline $\begin{aligned} \boldsymbol{\varepsilon} /: & / \mathrm{o} / \\
& (146)\left[\mathrm{i}^{\prime} \mathrm{t} \varepsilon\right] \\
& (147)\left[\mathrm{i}^{\prime} \mathrm{t}\right]\end{aligned}$ & $\begin{array}{l}\text { /ite/ } \\
\text { /itJ/ }\end{array}$ & $\begin{array}{l}\text { 'perna' } \\
\text { 'olho' }\end{array}$ \\
\hline
\end{tabular}

\subsection{Contraste entre vogais orais e vogais nasais}

\begin{tabular}{|c|c|c|}
\hline Fonética & Fonologia & Português \\
\hline $\begin{array}{l}/ \mathbf{i} /: \text { / } / \mathbf{i} / \\
\quad(148)\left[\text { pi. }^{\prime} \mathrm{tit}^{\mathrm{h}}\right] \\
\quad(149)\left[\mathrm{pi.}{ }^{\prime} \mathrm{tit}^{\mathrm{h}}\right]\end{array}$ & /pitit/ & $\begin{array}{l}\text { 'número 1' } \\
\text { 'pesado' }\end{array}$ \\
\hline 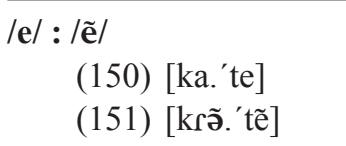 & $\begin{array}{l}\text { /kate/ } \\
\text { /krãtẽ/ }\end{array}$ & $\begin{array}{l}\text { 'valente' } \\
\text { 'nadar' }\end{array}$ \\
\hline 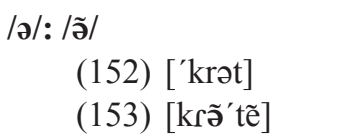 & $\begin{array}{l}\text { /krat/ } \\
\text { /krãtẽ/ }\end{array}$ & $\begin{array}{l}\text { 'nariz' } \\
\text { 'nadar' }\end{array}$ \\
\hline 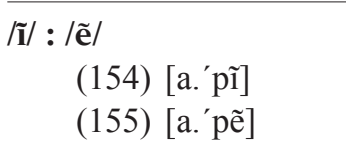 & $\begin{array}{l}\text { /apĩ// } \\
\text { /apẽ// }\end{array}$ & $\begin{array}{l}\text { 'apagar' } \\
\text { 'dia seguinte' }\end{array}$ \\
\hline $\begin{aligned} / \tilde{\mathbf{z}} /: & / \tilde{\mathbf{e}} / \\
& (156)\left[\mathrm{a} \cdot{ }^{\prime} \mathrm{p} \tilde{\mathbf{z}}\right] \\
& (157) \text { [a.'pẽ] }\end{aligned}$ & $\begin{array}{l}\text { /ap̃̃/ } \\
\text { /apẽ/ }\end{array}$ & $\begin{array}{l}\text { 'cheirar' } \\
\text { 'dia' }\end{array}$ \\
\hline $\begin{array}{l}\tilde{\mathbf{x}} /: \text { : } \mathbf{\mathbf { i }} / \\
\left.\quad(158) \text { [pa.mũ.' } 3^{\tilde{\mathbf{1}}}\right] \\
\quad(159)[\text { mpo.'31] }\end{array}$ & 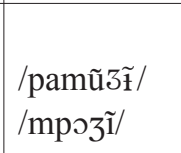 & $\begin{array}{l}\text { 'eu sentei' } \\
\text { 'carne' }\end{array}$ \\
\hline $\begin{array}{l}\tilde{\mathbf{o}} /: \text { : } / \tilde{\mathbf{u}} / \\
\quad(160) \text { [nũ.a.'re] } \\
\quad(161) \text { [nõr.'hõ] }\end{array}$ & $\begin{array}{l}\text { / nũare/ } \\
\text { /nõrhõ/ }\end{array}$ & $\begin{array}{l}\text { ‘não’ } \\
\text { ‘dormir’ }\end{array}$ \\
\hline
\end{tabular}

\section{Ambientes de ocorrência de segmentos consonantais}

As consoantes oclusivas / $\mathrm{p}, \mathrm{k}, \mathrm{t}$ / ocorrem combinadas com todas as vogais orais em sílabas $\mathrm{CV}(\mathrm{C})$, exceto por $/ \mathrm{k} /$ diante de $/ \varepsilon /$. Quanto às nasais, $/ \mathrm{p} /$ ocorre com 04 das 06 vogais nasais, deixando de ocorrer com $/ \tilde{\mathrm{z}} / \mathrm{e} /$

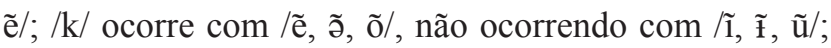
e /t/ ocorre com / $\tilde{1}$, ẽ, ũ/, deixando de ocorrer com

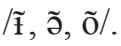

Essas consoantes apresentam 02 alofones cada: $[\mathrm{p}, \mathrm{k}, \mathrm{t}]$ ocorrendo em posição de início de sílaba (onset) $\mathrm{e}\left[\mathrm{p}^{\mathrm{h}}, \mathrm{k}^{\mathrm{h}}, \mathrm{t}^{\mathrm{h}}\right]$ em posição de final de sílaba (coda).

$/ \mathrm{p} / \mathrm{e} / \mathrm{k} /$ ocorrem seguidas de / $\mathrm{r} /$. [pr] ocorre diante das vogais orais /o, e, u, $\mathfrak{i} /$ e das nasais /ã, ẽ/. [kr] ocorre diante das vogais orais $/ a, \partial, \varepsilon, i, o, \rho, u, \dot{\mathrm{i}} / \mathrm{e}$ das nasais $/ \widetilde{\partial}$, ĩ/. A terceira oclusiva, /t/, não se combina com /r/.

A consoante tepe ocorre com seis vogais orais $/ \mathrm{a}, \mathrm{i}$, e, i,, , $\varepsilon /$, mas não com / $/, 3, u, o /$. Ocorre também com $/ \tilde{\partial}, \tilde{\mathrm{u}} /$.

As consoantes nasais $/ \mathrm{m}, \mathrm{n} /$ ocorrem da seguinte maneira em Kyikatêjê; a bilabial $/ \mathrm{m} /$ ocorre, na maioria das vezes, com as vogais nasais, /̃̃, ẽ, ĩ, ũ, õ/; há também a ocorrência de $/ \mathrm{m} /$ com duas vogais orais, /a, e/. $/ \mathrm{n} /$ ocorre com as vogais orais $/ \mathrm{u}, \mathrm{o}, \mathrm{a}, \partial$, e/ e com as nasais /ũ, õ, ẽ, כ̃/.

A consoante africada palatal/tg/ ocorre em Kyikatêjê com quase todas as vogais orais, deixando de ocorrer somente com $/ \supset, \varepsilon /$. Quanto às nasais, tal consoante ocorre apenas com $/ \tilde{\mathrm{o}}, \tilde{\mathrm{u}} /$.

A consoante fricativa glotal $/ \mathrm{h} /$ ocorre com quase todas as vogais orais, deixando de ocorrer somente com $/ \varepsilon, \rho, \mathrm{u} / ;$ quanto às nasais, $/ \mathrm{h} /$ ocorre com $/ \tilde{1}$, ̃̃, õ $/$.

A aproximante palatal $/ \mathrm{j} /$ parece ocorrer em Kyikatêjê em distribuição complementar com [3], diante das vogais altas nasais $/ \tilde{\mathrm{f}}, \tilde{\mathrm{i}} /$, e com [j], diante de outras vogais, em início ou final de sílaba.

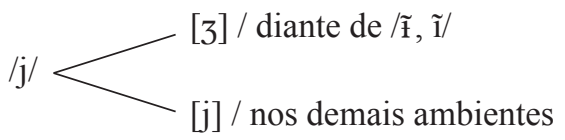

A aproximante labiovelar vozeada ocorre em Kyikatêjê em início e final de sílaba e apenas com a vogal central baixa /a/.

\section{Padrões silábicos da língua Kyikatêjê}

Todas as línguas humanas obedecem regras que determinam a organização interna de seus elementos. Assim, as sílabas ou padrões silábicos respeitam os agrupamentos e as sequências de seus segmentos como convém ao funcionamento do sistema linguístico. 
No presente trabalho, os padrões silábicos serão apresentados conforme o modelo binário:

$\longrightarrow$ Onset e Rima; Rima $\longrightarrow$ Núcleo e Coda, presente em Pike e Pike (1947 apud MENDONÇA, 2003, p. 25).

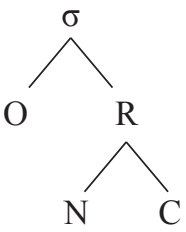

Esse modelo assegura que a sílaba possui dois ramos, o primeiro (onset) contendo até 02 consoantes e o segundo (Rima) contendo, por sua vez, o núcleo (vogal) e a coda (consoante).

Pode-se considerar que a língua Kyikatêjê apresenta os seguintes padrões silábicos: V; VC; CV; CVC; CCV: e CCVC. Esses padrões parecem ser bem comuns às línguas Jê, sendo encontrados em Parkatêjê (ARAÚJO, 1989, p. 24), Tapayúna (CAMARGO, 2010, p. 94) e Pykobjê (AMADO, 2004, p. 27).

$\mathrm{O}$ acento em Kyikatêjê é predominante na última sílaba, ocorrendo somente poucos dados em que o acento recai na penúltima sílaba. Os dados abaixo mostram o acento na última sílaba, que é o padrão mais comum na língua.

$\begin{array}{ll}\text { - /ha.'ra/ } & \text { 'pena' } \\ \text { - /he.'ti/ } & \text { 'aranha' } \\ \text {-/'krĩ.ri/ } & \text { 'cupim' } \\ \text {-/'kru.wa/ } & \text { 'flecha' }\end{array}$

Assim como em outras línguas Timbira, como Pykobjê (AMADO, 2004 p. 31), e Apãniekrá (ALVES, 2004, p. 44), e línguas Jê, como Tapayúna (CAMARGO, 2010, p. 98) a frequência do acento é recorrente em Kyikatêjê.

Durante a realização deste trabalho, foram observadas algumas realizações complexas envolvendo os segmentos silábicos do Kyikatêjê. Essas realizações compõem o corpo dos dados presentes neste estudo, porém as particularidades de suas ocorrências não foram detalhadamente descritas, uma vez que era necessário um estudo aprofundado sobre as razões que fornecem essas ocorrências. Vejamos quais são as ocorrências:

- A composição da oclusiva /p/ mais a tepe $/ \mathrm{r} /=[\mathrm{pr}]$, que possui realizações apenas com as vogais altas e médias fechadas $/ \dot{i}, o, e, u, \tilde{e}, \tilde{a} /$, não ocorrendo com vogais baixas ou abertas.

- A ocorrência do fone [mp]. Sobre este fone, Araújo (1977, p. 120) destaca a ocorrência das seguintes consoantes pré-nasalizadas em Parkatêjê /mp, nt, nk, nh/, porém essas ocorrências não foram evidenciadas em Kyikatêjê, exceto a bilabial prénasalizada [mp] nas seguintes palavras (mpo.' $f o$, mpo.'zĩ, mpa.jõ.'kra, mpej). Foi observado que [mp] não ocorre com vogais nasais. $/ \mathrm{m} /$ ocorre, sobretudo, com vogais nasais, o que possibilitaria uma interpretação dos elementos como em distribuição complementar, porém $/ \mathrm{m} /$ também ocorre com as vogais orais $/ a, u /$ o que inviabiliza tal interpretação.

É importante ressaltar que não foi possível apresentar a listagem completa dos pares em contraste com os dados analisados. Ficaram pendentes os seguintes pares $/ \mathbf{i} /: / \partial /$, $/ \mathrm{u} /: / \mathrm{o} / \mathrm{e} / \varepsilon /: / 3 /$. O par [ko] 'água' e [ko] 'molhar' que, para a fonologia, é um tanto problemático por conta da questão semântica envolvida, teve sua distinção bem marcada pelo falante Kyikatêjê.

Outra observação diz respeito a alguns itens lexicais distintos da perspectiva fonético-fonológica entre Kyikatêjê e Parkatêjê. Foram os seguintes dados encontrados: [i.ju.a.'hi] / [ku.'pə] 'abraçar'; [i'tu] / [te.'ki] 'barriga'; [in.kri.'re] / [a.kra.i.nũ.' $r \varepsilon]$ 'pequeno' e [ka.'re] / ['pu.ru], os quais são Kyikatêjê e Parkatêjê, respectivamente.

\section{Conclusão}

O trabalho ora apresentado, embora deixe algumas questões em aberto, no âmbito fonético, indica que Kyikatêjê apresenta um repertório de 34 sons, 16 vocálicos e 18 consonantais, a maioria comuns às línguas do complexo dialetal Timbira (Parkatêjê (Araújo, 1977 p. 15), Pykobjê (Amado, 2004, p. 16) e às línguas Jê, como Tapayúna (Camargo, 2010, p. 41)). Das vogais, 10 são orais e 06 são nasais. Com relação às consoantes, a língua apresenta 12 sons, 07 são oclusivas: 01 bilabial [p], 01 alveolar [t], 01 velar [k], estas 03 oclusivas também ocorrem com aspiração $\left[\mathrm{p}^{\mathrm{h}}, \mathrm{t}^{\mathrm{h}}, \mathrm{k}^{\mathrm{h}}\right]$. Há 01 glotal [?]; 01 africada [ $[\mathrm{f}]$; 03 fricativas: uma labiodental $[\beta]$, uma pós-alveolar [3] e uma glotal [h]; 03 nasais: 01 bilabial $[\mathrm{m}]$, que também ocorre seguida por [p], ou seja, [mp]; uma alveolar [n] e uma velar [n]; um tepe [r] e por fim, duas aproximantes: uma bilabial [w] e uma palatal [j].

Quanto aos fonemas, pode-se afirmar, preliminarmente, que o Kyikatêjê possui 26 fonemas, divididos em 10 consoantes e 16 vogais: 10 orais e 06 nasais, o que é idêntico à língua Parkatêjê.

Os fonemas oclusivos possuem 02 alofones cada, $[\mathrm{p}, \mathrm{k}, \mathrm{t}]$, ocorrendo em início de sílaba e $\left[\mathrm{p}^{\mathrm{h}}, \mathrm{k}^{\mathrm{h}}, \mathrm{t}^{\mathrm{h}}\right]$ em final de sílaba. A consoante palatal /j/, quando palatalizada, realiza-se como [3], ocorrendo diante das vogais altas nasais $/ \tilde{\mathrm{f}}, \tilde{\mathrm{i}} /$; e [j] diante de outras vogais, em início ou final de sílaba. 
No que diz respeito ao padrão silábico, além do padrão universal $(\mathrm{CV})$, a língua também apresenta estes padrões: $\mathrm{V}, \mathrm{VC}, \mathrm{CVC}, \mathrm{CCV}$ e $\mathrm{CCVC}$ todos comuns às línguas Jê. $\mathrm{O}$ acento em Kyikatêjê, como é recorrente em Pykobjê (AMADO, 2004 p. 31), Apãniekrá (ALVES, 2004, p. 44) e Tapayúna (CAMARGO, 2010, p. 98), recai com mais frequência na última sílaba.

\section{Referências}

ALVES, Flávia de C. O timbira falado pelo Canela Apãniekrá: uma contribuição aos estudos da morfossintaxe de uma língua Jê. Campinas: Unicamp, 2004.

ARAÚJO, Leopoldina M. S. Estruturas subjacentes de alguns tipos de frases declarativas afirmativas do Gavião-Jê. Dissertação (Mestrado) - Universidade Federal de Santa Catarina, Florianópolis, 1977.

ARAÚJO, Leopoldina M. S. Aspectos da língua Gavião-Jê. Tese de doutorado. Rio de Janeiro: UFRJ, 1989.

AMADO, Rosane de Sá. Aspectos morfofonológicos do GaviãoPykobjê. Tese (Doutorado) - Universidade de São Paulo, São Paulo, 2004.

CAMARGO, Nayara da Silva. Aspectos socioliguísticos e uma análise fonológica preliminar. Dissertação (Mestrado) Campinas, Unicamp, 2010.

CALLOU, Dinah. LEITE, Yonne. Iniciação à fonética e a fonologia. 8. ed. Rio de Janeiro: Jorge Zahar Ed., 2001.
FERRAZ, Iara. Enciclopédia dos povos indigenas no Brasil. Janeiro, 2000. Disponível em: <http://pib.socioambiental. org/pt/povo/gaviao-parkateje/print>. Acesso em: 14 mar. 2012

FERREIRA, Marília. Estudo Morfossintático da língua Parkatêjê. Tese (Doutorado) - Campinas, Unicamp, 2003.

FERNANDES, Rosani de Fátima. Educação Escolar Kyikatêjê: novos caminhos para aprender e ensinar. Dissertação (Mestrado) - Universidade Federal do Pará, Belém, 2010.

KINDELL. G. E. Guia de análise fonológica. Brasília, DF: Summer Institute of Linguistics. 1981.

MELATTI, Julio Cezar. Por que a aldeia Krahó é redonda? Informativo Funai, Brasília, v. 11/12, p. 34-41, 1974.

MOORE; GALUCIO; GABAS Jr. O desafio de documentar e preservar as línguas amazônicas. Revista Scientific American, v. 3, 2008 .

SOARES, Elaine Pereira Machado. FARIAS, Carmélia Gonçalves Farias. Notas sobre a situação sociolinguística da comunidade indígena Kyikatêjê Amtàtí. In: CABRAL, Ana Suelly. RODRIGUES, Aryon Dall'Igna. LOPES, Jorge Domingues, JULIÃO, Maria Risoleta Silva (Org.). Linguas e culturas Tupí; Linguas e culturas Macro-Jê. Campinas: Curt Nimuendajú; Brasília: LALI/UnB, 2001.

Recebido: 30 de agosto de 2013

Aprovado: 23 de novembro de 2013

Contato: mariliaferreira1@gmail.com 